\title{
Research on the Application of Multimedia Technology in Film and Television Arts Education
}

\author{
Meiyue Li \\ JiLin Business and Technology College, JiLin, ChangChun 130062 \\ hunter2011@foxmail.com
}

Keywords: Film and Television Arts Education, Multimedia Technology, Application

\begin{abstract}
The film and television arts education integrated the nature of film and television art, in the form of education it reflected as intuitive visual modeling, rich sound and picture language, the imaging content presentation with the specialty popularization of film and television art. Compared with traditional education forms, film and television arts education should begin with the combination with multimedia educational tools to be the model for modern education. The application of multimedia educational tools in film and television arts education will develop quickly with the development of high-tech and update educational philosophy of film and television art inevitably followed by a new change era.
\end{abstract}

\section{Introduction}

Film and TV Arts combines drama, literature, painting, sculpture, music, architecture, photography, dance, art and other elements, and these elements have been fused into the film after each other, forming a feature film, television itself, making the film becomes a independent art. More importantly, both visual art film art itself, but also the auditory art; both time arts, but also a space for the arts. It is because of Television Arts itself has a comprehensive aesthetic features, that it can and visual and auditory, time and space, dynamic and static performance and reproduction in one.

Film and TV Arts itself has aesthetic educational role. Aesthetic effect visual arts mainly refers to people through television art appreciation activities, by truth, goodness and beauty influence and infection by outstanding film and television works subtle, entertaining, emotional role of people, causing people to thoughts, feelings, ideals, the pursuit of undergoing profound changes, help people establish a correct outlook on life and world view [1].

\section{The Research on Film and Television Art Education}

The object of Television Arts Education in a sense is the television audience, they are a wide number of people, a complex, interesting and diverse large groups. With greatly enhance the social and material standard of living, people's demand for film and television arts, including spiritual life is also growing. However, because of the theory of film art criticism, especially film art appreciation lagging behind theoretical studies and film culture education, resulting in a lack of knowledge of the general audience the film culture and accomplishment, which hinder the improvement of film art and appreciation levels. Therefore, the quality of education in the majority of young people in the film and television arts education as an important part of aesthetic education, should get people's attention.

The nature of film and television arts education Chaintech visual arts, in the form of education exhibit intuitive visual modeling, rich sound and picture language, the image content presentation, with the popularization of specialty film and television art, and therefore, it has the most popular of the Advantage. Compared to traditional books, word of mouth, a blackboard form of education, film education should begin and multimedia educational tools in combination, as a model for modern education [2]. 


\section{The Definition and Connotation of Multimedia Teaching Techniques}

Multimedia refers to the teaching process, according to the characteristics of teaching objectives and teaching object through instructional design, rational selection and use of modern teaching media and organic combination with traditional teaching methods, to participate in the whole process of teaching, the role of information in a variety of media the student to form a rational structure of the teaching process, to achieve optimal teaching effect.

Multimedia has begun to appear in the 1980 s, but was using a variety of electronic media such as slide projector audio, video and other comprehensive used classroom teaching. This teaching technique known as a multimedia combination of teaching or electronic teaching. Since the 1990s, with the rapid development of computer technology and the popularity of multimedia computer has gradually replaced the previous status of the integrated use of a variety of instructional media. So now we usually refer to teaching, it is specific to the use of multimedia computers and teaching activities by means of pre-produced multimedia educational software to carry out. It can be called a computer-assisted instruction.

Multimedia Computer Assisted Instruction refers to the use of multimedia computers, integrated processing and control symbols, language, text, sound, graphics, images, video and other media information, according to the various elements of multimedia teaching requirements, organically combined and through the screen or projector projector displayed; press the need to add sound cooperation, and human-machine interaction between user and computer, complete the teaching or training process.

Movies, television in the sense that technology is the core component of modern multimedia. Media education is largely emphasized that rich information voices among prominent forms of education, the picture is the shape formed. These shows feature multimedia education and Television Arts Education has numerous class of endogenous, a multimedia education should be first carrier means and forms of video art education.

Compared with traditional teaching methods, after multimedia teaching entering the film and television art, it reflects the following advantages [3]:

Exhibit the Visual Aesthetic Characteristics of Visual Arts. Television on the external form of artistic expression, primarily visual style. The use of computer-assisted instruction, the ability to work in film and television graphics, images, sound, language, text and other images visually presented symbols, objects of teaching to enhance students impression and understanding. You can maximize the visual styling feature film and television arts.

The Knowledge Capacity in Per Unit of Curriculum Is Large. Tech as an intermediary to complete knowledge of teaching and learning, for teachers, can learn more by their own will arrange teaching activities, classroom atmosphere omitted control, emergency treatment and other projects, will be more fully the time is used to explain the knowledge up. Students can choose according to their actual situation and arrangements've learned, eliminating many optional link, thus greatly improving the efficiency of learning.

It Has Improved the Students' Learning Interest and Initiative. Multimedia teaching has changed the traditional teaching than a single, rigid classroom model, using intelligent type, having an affinity interface to vivid, user-friendly way, to show the most advanced and extensive knowledge in order to stimulate students' learning motivation, encourage students to better serve as the main learning this role.

Sharing the Educational Resources, Saving Manpower and Material Resources. This is associated with its own characteristics of multimedia teaching. Traditional teaching tends to be a teacher to guide dozens of students, and multimedia teaching, a teacher teach, by having a very broad audience and multimedia transmission, its beneficiaries are thousand, million dollars. In addition, a new teaching achievements, a person's innovations spread through the Internet, will benefit others. Especially in improving the students' interest and initiative, the multimedia teaching to enter the film and television arts education with a more unique advantage.Specific features:

static to dynamic, stimulate interest in learning. Something dynamic than static things that arouse students 'attention, better mobilize the interest of students, to stimulate students' interest in learning. 
Dynamic characteristics in itself is the basic characteristic visual arts. Multimedia educational means of intervention, to maximize and strengthen this basic features.

Multimedia teaching can create a lively and interesting teaching situation, a silent to sound, static to dynamic, stimulate student interest in learning, improve student learning initiative. In traditional teaching, student-oriented static dull textbooks and writing on the blackboard, inevitably boring. Computer Multimedia overcome this defect, such as theoretical knowledge syllabus of these stationary text can be moved according to the specified track as static graphics can be moved like animation, you can change the color, speed can be controlled, to facilitate students to focus on theoretical knowledge intensive type of memory and understanding. The image with motion characteristics of audiovisual modeling, multimedia technology can be intuitive interpretation, enhance students observe, appreciation, interest analysis, thus providing the necessary audio-visual experience for teachers to guide and inspire.

The change anything easy, increase interest in learning. Computer Multimedia energy simulation, of the abstract image. It can not only set text, pictures, images, sounds in one, the student into the vivid and colorful among the teaching situation, it enables students to accept sensory stimulation, develop thinking skills, students expand the concept of space, deepen understanding of things, greatly reducing the difficulty of student cognitive change anything easy.

Computer multimedia teaching can break the constraints of time and space, the extension and broadening of teaching time and space. Through images, sounds, colors and animations, teaching information transfer, to solve the teaching difficulties due to limitations of space and time caused by so learning content easier to understand and grasp, nurture and develop the students' access to information, analysis and processing of information capability information [4].

Entertaining, cultivate interest in learning. Computer multimedia features are maps, text, sound, image, and Mao, to provide various forms to students with different functions emotional material. Vivid images, realistic scenarios standard reading, pleasant background music, wit and a puzzle game, the students into relaxed pleasant learning environment for students to take the initiative to explore, proactive, so that students learn, willing to learn and enjoy learning.

Television Television Arts Education in addition to aesthetic education, film appreciation education, as well as a more realistic sense of film and television creative education. Multimedia can be partially simulated video creation scenarios for students through their training, to participate in the film and television creative practice, we found problems in practice and solve problems.

\section{The Problems Attention Should be paid to in the Applicaion of Multimedia Technology in Film and Television Arts Education}

Multimedia despite a lot of convenience for the film and television arts education, but in a wide range of multimedia teaching to enter the film arts education, we should pay attention to the following issues:

People-Centered and Teacher-Based. Multimedia teaching methods artificially separated organic link between teachers and learners, the development of multimedia teaching is taboo. If the teacher to show video art multimedia material without adequate theoretical insights and implement ability, he just step by step operation of multimedia courseware, according to prearranged lesson plans to talk; or in lectures, lack of communication with the students, the students have some doubt, faced with multimedia "dead model", but can not be afraid of the teacher embarrassed to say, this will cause the students to learn and not real, granted the teacher rather than deep, reach lesson outline requirements, this class has become a courseware demonstration lesson, ignoring the leading role of teachers, students' dominant position.

Correct understanding should be: the teaching process is a complex process, is the inclusion of teacher education thought understanding, adequate and reasonable use of the experience of teachers, teachers' understanding of the student, the student's learning attitude, teaching resources, and the implementation of complex and delicate process of bilateral activities between teachers and students, etc., including process [5].

Pay Attention to Differentiation and Give Reasonable Guides. For the visual arts to 
understand and learn in a traditional classroom, students are good and bad, in the multimedia teaching, this problem will become more prominent. Those self-control and strong, strong ability to accept, television itself has a certain artistic accomplishments of students themselves, and the more the better school; and those weak self-control, the ability to accept, the lack of basic quality film and television arts students will exclude some of their not interested content. Poor motivation to learn, will learn more the more worse, this is bound to lead to polarization, thus further affecting the quality of teaching. Therefore, teachers in the teaching process should take into account the actual situation, pay attention to student feedback information among the film and television arts learning, strengthen guidance.

To Save Costs and Use Scientificly. Multimedia education equipment high input costs, film and television arts related multimedia educational materials tend to be more time-consuming, production processes and technology is relatively complicated. Therefore, after the introduction of the device if the lack of courseware production advanced technology, lack of talent, or courseware production is too simple, you can not make full use of the advantages of leaving equipment idle equipment, resulting in a waste of resources, and lack of technical maintenance led to serious loss of equipment, Such a waste of a wit, human and material resources. Therefore, even though video and multimedia education art education is closely related role, but in the application of multimedia technology to video art of teaching, should give full consideration to cost savings, the use of scientific problems.

\section{Conclusions}

The most appropriate application of multimedia educational means is in the film and television arts education. With the development of high technology, video art education inevitably achieved new changes from the means to meaning followed by a new era. The aesthetic feature of film and television determines their natural advantage of multimedia education means in advance. With the popularity of computers education and networks education, the modernization of traditional media education has already begun and modern film art education has developed rapidly. The multimedia will bring revolutionary changes in the traditional film and television arts education.

\section{References}

[1] Yu Xiao: Journal of Kaifeng Education Institute, Vol. 1 (2014) No 14, p21-25

[2] Haiyan Li: Music Space, Vol. 9 (2014) No 27, p.82-90

[3] Ting Sun: China Educational Technique Equipment, Vol. 1 (2013) No 22, p.11-14

[4] Chenguang Zhu: Northern Music, Vol. 12 (2011) No33, p.121-124

[5] Lili Dong: Journal of Guizhou University, Vol. 5 (2011) No27, p.59-63 